\title{
DISCUSSION
}

\section{A back-analysis of Beliche Dam}

\author{
D. J. NAYLOR, J. R. MARANHA, E. MARANHA DAS NEVES and A. A. VEIGA PINTO (1997). \\ Géotechnique 47, No. 2, 221-233
}

L. Pagano, F. Silvestri and F. Vinale, University of Naples 'FEDERICO II'

The authors' work was mainly devoted to diagnosing the mechanisms that determined the particular settlement field during the construction and impounding stages of Beliche Dam. The numerical back-analysis was conducted using the 'known pore pressure change' technique (i.e. by introducing the measured evolution of the pore pressure field as input data for the analysis).

The approach followed makes it possible to study the problem as uncoupled; by eliminating the uncertainties related to hydraulic effects on the soil skeleton, significant numerical simplifications are introduced. It is an appropriate diagnostic tool provided that the pore pressure field is continuously monitored, but it is obviously not suitable as a prediction method.

The fine-grained core was modelled neglecting the effects related to the changes in saturation degree and suction (occuring in the very initial construction states); its mechanical properties were then obtained from conventional laboratory tests.

In the period between the dates of submission and publication of this paper, progress in updating experimental techniques and advances in constitutive modelling of unsaturated soils have shown (e.g. Burland \& Ridley, 1996; Rampino, 1997) that, starting from a state close to full saturation, even small changes in the moisture content might significantly affect the mechanical response of compacted fine-grained soils, such as the core material of Beliche Dam.

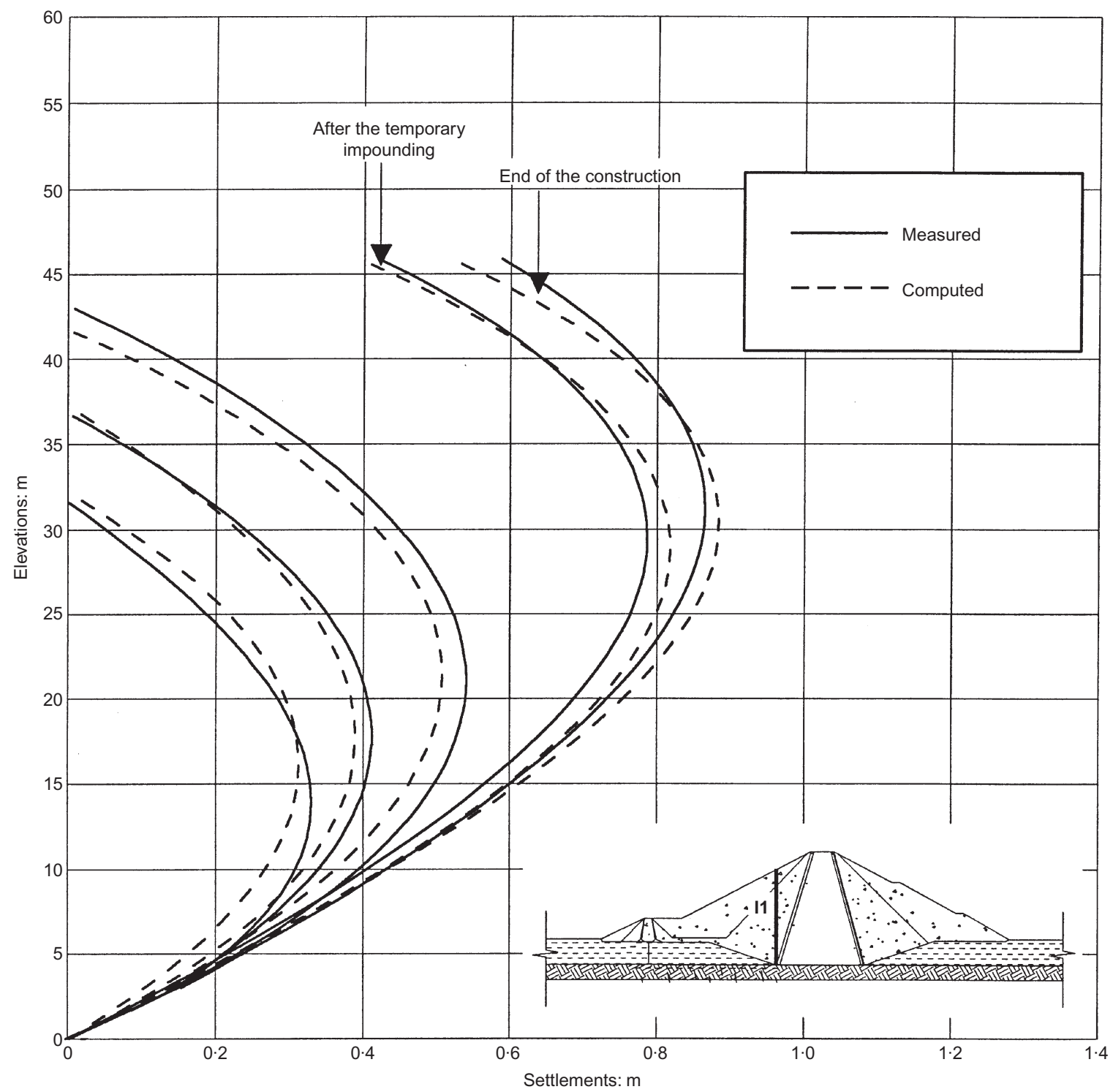

Fig. 16. Interpolated settlement profiles from measurements and calculations at inclinometer I1 
Since the experimental data from laboratory tests and monitoring of Beliche Dam were kindly provided by LNEC to the writers, the potential of a three-phase model for the core was tested (Pagano, 1996; Pagano et al., 1997) as a suitable tool for both class A and class B predictions.

A back-analysis of the dam was carried out assuming most soil parameters as free variables of the problem, including those relevant to the constitutive law of the core. The numerically simulated behaviour of the dam was compared with that observed in terms of both displacement and pore pressure fields, these latter no more to be considered as a priori known.

A 'coupled unsaturated approach' was followed, using the finite element method to solve the equilibrium and water continuity equations, including the degree of saturation into the variables, and defining the 'retention characteristic curve' relating the suction to the degree of saturation. The constitutive law of the core was defined by a Cam clay model, referring to the Bishop expression for effective stresses.

The model was tested trying to best-fit the available monitoring data in terms of settlement profiles at locations $\mathrm{I} 1-\mathrm{I} 3$, and pore pressures at piezometer P7. The reference time interval for the best-fitting procedure was limited to the construction stages, including the temporary impounding following the extraordinary rainfall event. The reliability of the parameters obtained was confirmed by the agreement between measurements and calculations on different locations and out of the reference time interval; that is, after the end of construction. The comparisons between computed and measured settlement profiles are shown in Figs 16 and 17, and the pore pressure time histories in Figs $18-20$.

From the back-analysis, the resulting value of the initial suction in the core was as low as $50 \mathrm{kPa}$, confirming the assumption made by the authors.

The back-analysis iterative process also evidenced the strong sensitivity of settlement and pore pressure predictions to even small changes of initial suction. These latter influence the extension of the range inside which (I-S in Fig 21) an unsaturated and 'undrained compressible' state of the material subsists, before stepping into a saturated ('undrained uncompressible') state $(\mathrm{S}-\mathrm{H}-\mathrm{C})$. Therefore the saturation substantially affects the settlement and pore pressure fields, particularly for zoned dams with wet cores that rapidly approach saturation during construction. If the evolution of the pore pressure field is recorded (i.e. a diagnostic study is carried out), such effects should be implicitly accounted for, by means of the "known pore pressure changes' technique.

In the case of Beliche Dam, some of the pore pressure observations during construction underwent setbacks during the period when a collapse occurred in the upstream shell (Pagano et al., 1997). The back-analysis highlights the fact that a significant part of the piezometric head measured at the end of the construction (about $100 \mathrm{kPa}$ at the core axis at elevation $22.5 \mathrm{~m}$;

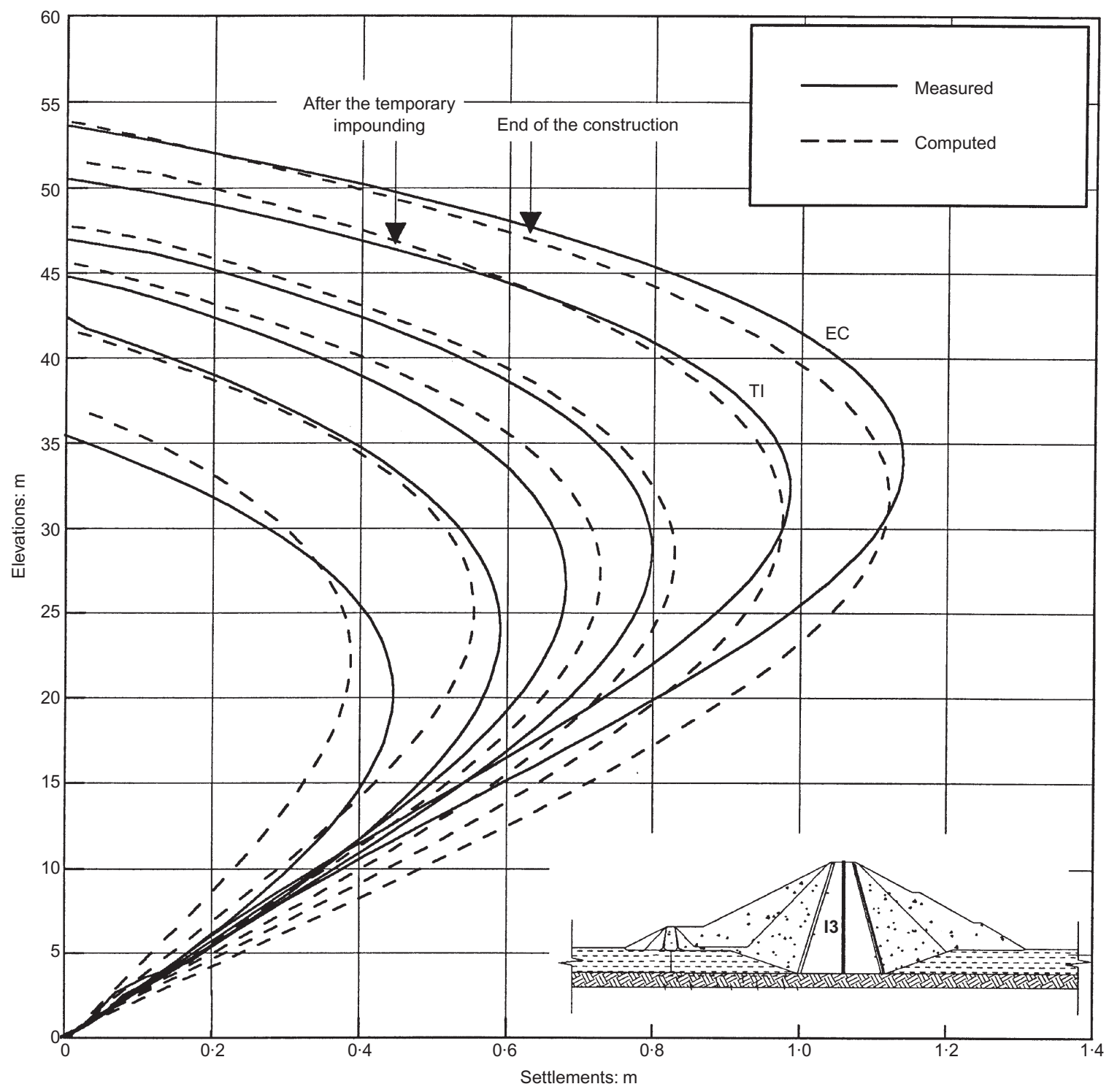

Fig. 17. Interpolated settlement profiles from measurements and calculations at inclinometer I3 


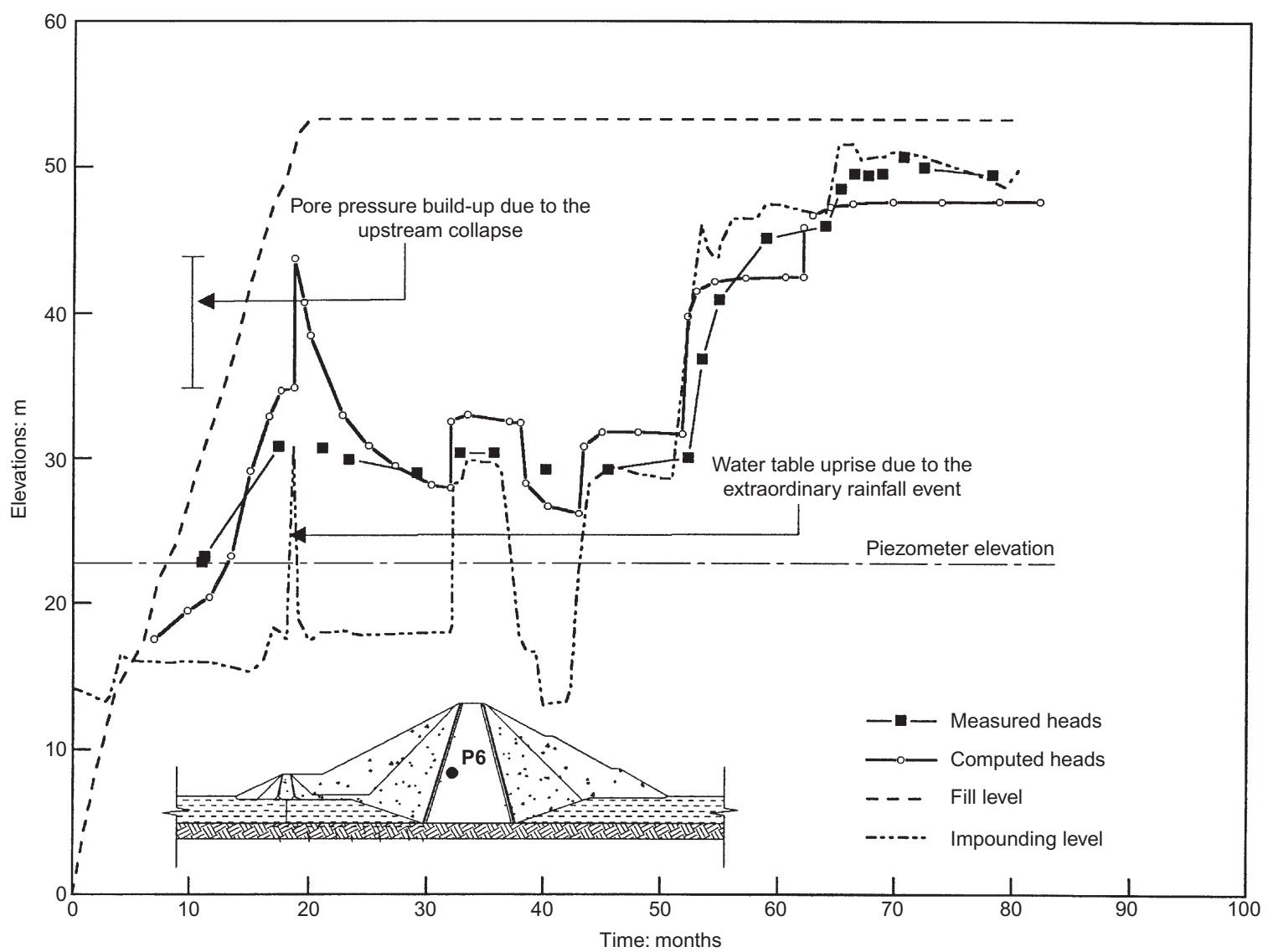

Fig. 18. Time history of fill and impounding levels together with measured and computed piezometric heads at location P6. The zero setting for the time scale corresponds to the beginning of the construction

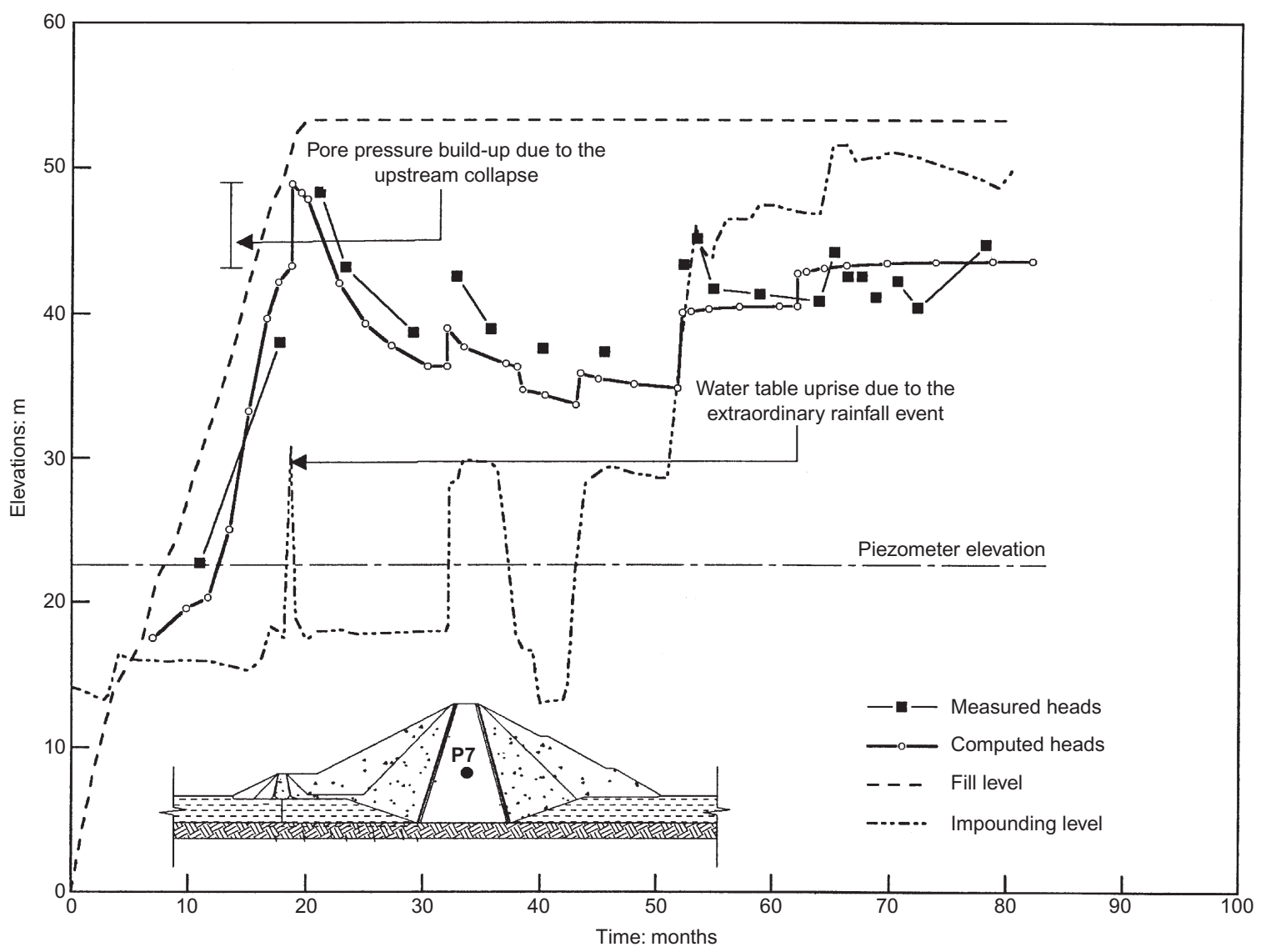

Fig. 19. Time history of fill and impounding levels together with measured and computed piezometric heads at location P7. The zero setting for the time scale corresponds to the beginning of the construction 


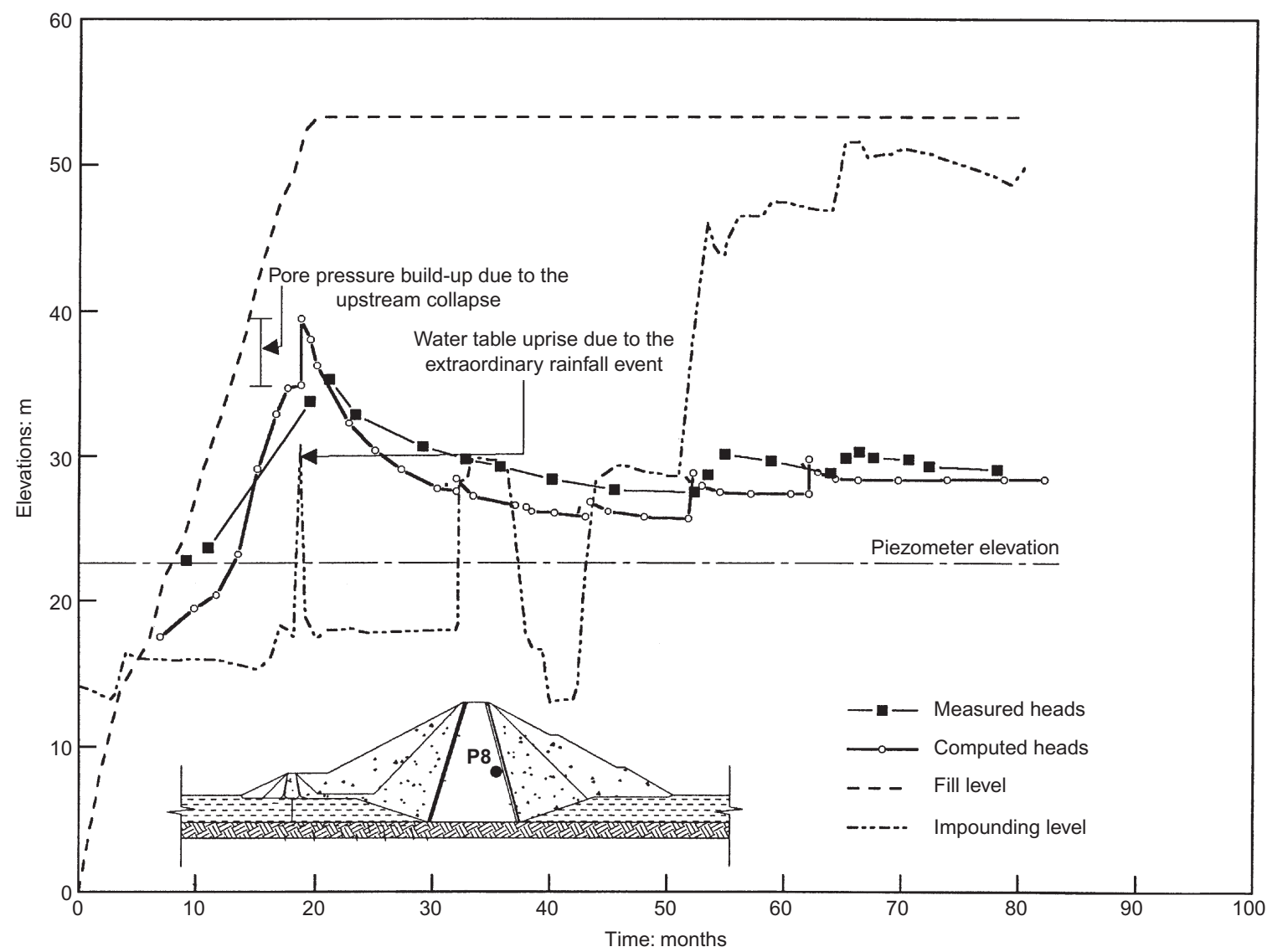

Fig. 20. Time history of fill and impounding levels together with measured and computed piezometric heads at location P8. The zero setting for the time scale corresponds to the beginning of the construction

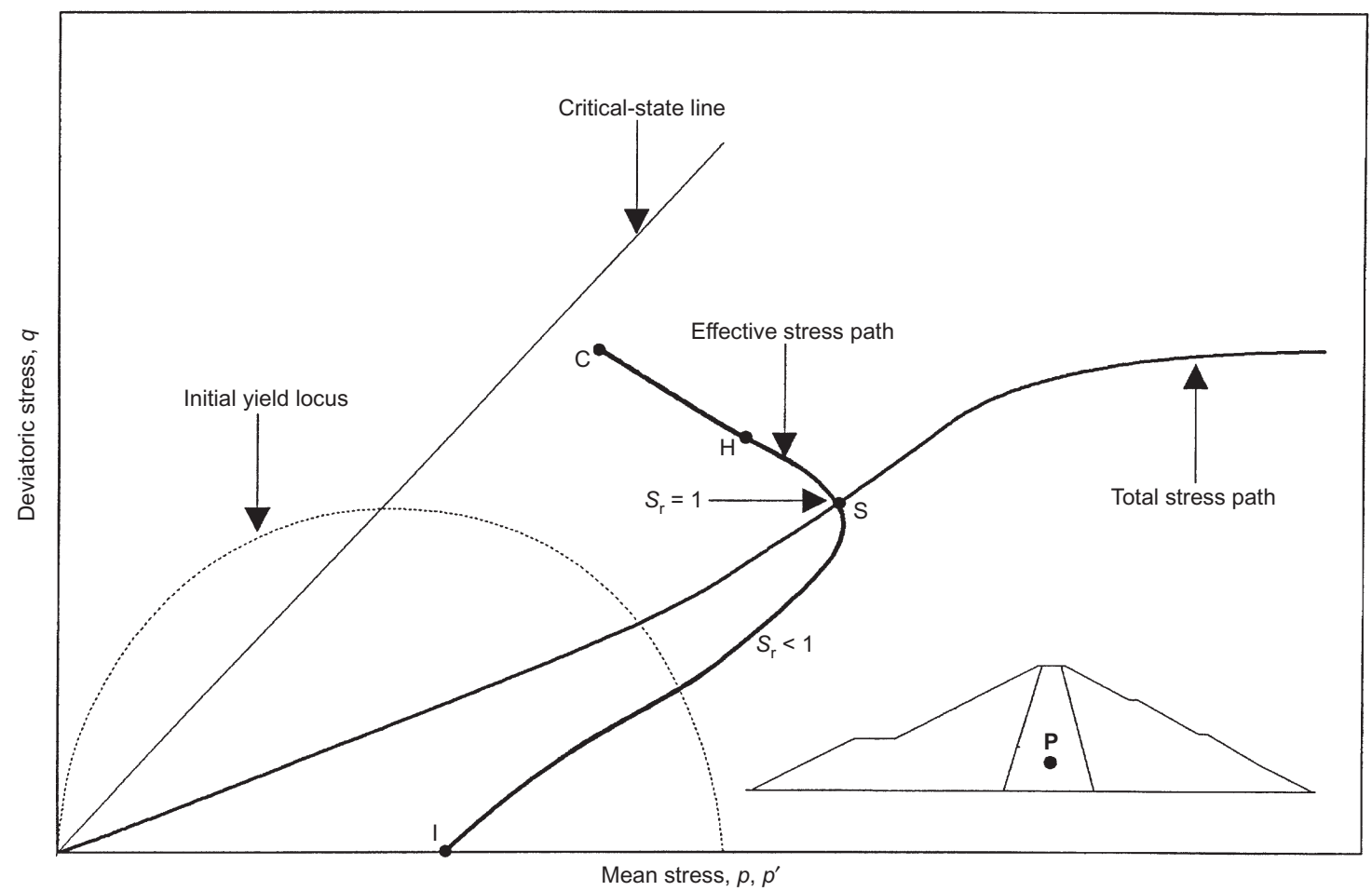

Fig. 21. Schematic total and effective stress paths pertaining to a point located in the core

see Fig 18) is produced by the collapse phenomenon that occurred in the upstream shell. The abrupt growth of pore pressure is generated by the quick, and therefore undrained, load transfer mechanism from shells to the core.
In conclusion, the approach followed was proved to be suitable in class A and class B predictions, and seems to be an appropriate diagnostic tool when problems related to lack of monitoring data arise. 


\section{Authors' reply}

The discussers have carried out coupled analyses that complement the 'known pore pressure change' analyses used in the paper. They appear to have obtained good agreement with the measurements. They make the point that both settlements and the construction pore pressures are sensitive to the initial suctions. We agree that this is the case. We believe, however, that the initial suctions played a relatively minor role in the behaviour of Beliche Dam.

By using a coupled approach they have been able to compute pore pressures for comparison with the measurements. The use of the 'known pore pressure change' technique in the paper simplified the back-analysis so that only the measured displacements and stresses needed to be matched, without the additional complication of matching pore pressures. This is a good way of obtaining meaningful effective stress parameters for later use in predictions. While there is clearly a role for coupled analyses, if they are to be used for predictions it needs to be shown that the results are not sensitive to the additional parameters required. The discussers have not addressed this question.

In response to the comment (made in reference to the uncoupled approach used in the paper) that it is obviously not suitable as a prediction method' we note that it is, if the pore pressure field is assessed independently. It may be either calculated separately or even just assessed on the basis of experience. The uncertainties in the pore pressure are thereby separated from the uncertainties in the finite element analysis.

The 'measured' values in their Figs 16 and 17 have apparently been smoothed. The full lines labelled 'After the temporary impounding' and 'End of the construction' presumably correspond to lines $\mathrm{C}$ and $\mathrm{E}$ respectively in Figs 4 and 5 in the paper. While for the most part these smoothed lines lie within $20 \%$ of the uneven measured profiles in Figs 4 and 5, in the case of line $\mathrm{C}$ for inclinometer $\mathrm{I} 3$ the discussers' line indicates measured settlements in the upper part of the dam some $40 \%$ higher than in the paper. Consequently the good agreement between computation and measurement indicated in Figs 16 and 17 would not be so good were the measured profiles from the paper used. We wonder how these differences came about, as presumably the data came from the same source.

The discussers state that their work applies to the construction and impounding stages. We wonder therefore where the 'computed heads' in the six years following impounding shown Fig. 18 come from.

It appears from Pagano et al. (1997) that the discussers idealised the rockfill as linear elastic, and used the NobariDuncan technique to model the collapse in it. This contrasts with the use of the elasto-plastic critical-state model in the paper not only for the core but for the shells as well, and the use of a generalisation of the Nobari-Duncan technique for modelling the collapse settlement. In the case of this dam, with its relatively soft rockfill, we believed that it was necessary to use an elasto-plastic model to reproduce the non-linear behaviour of the rockfill. The parameters were based on the preconstruction laboratory tests and, as has been shown in the paper, provide a reasonable representation of the material in the dam. We are therefore not enthusiastic about a linear elastic idealisation for the rockfill.

\section{REFERENCES}

Burland, J. B. and Ridley, A. M. (1996). The importance of suction in soil mechanics. Proc. XII Southeast Asian Geotechnical Conference, Kuala Lumpur.

Pagano, L. (1996). Static analysis of zoned earth dams. Doctoral thesis, University of Napoli (in Italian).

Pagano, L., Silvestri, F., Vinale, F. and Maranha das Neves, E. (1997). Coupled analysis of Beliche Dam. Proc. XIX Int. Conf. Large Dams, Firenze.

Rampino, C. (1997). Mechanical behaviour of a compacted and partially saturated silty sand. Doctoral thesis, University of Napoli (in Italian) 